\title{
Antenatal dexamethasone and subsequent lung growth
}

\author{
Y C WONG, C S BEARDSMORE, AND M SILVERMAN \\ Department of Paediatrics and Neonatal Medicine, Institute of Child Health, Hammersmith Hospital, London
}

SUMMARY Long-term effects on lung size and lung mechanics were sought in a 12-month follow-up study of 15 infants of very low birthweight $(<1500 \mathrm{~g})$, 7 of whom had been exposed to antepartum dexamethasone (mean dose $21 \mathrm{mg}$ ). None of the infants had significant neonatal respiratory disease. No differences were found between dexamethasone-treated and control groups for thoracic gas volume, dynamic pulmonary compliance, or airways resistance during the first year of life. This suggests that the growth and development of the lungs are not adversely affected by antepartum exposure to dexamethasone.

The value of antenatal corticosteroid administration in the prevention of the respiratory distress syndrome in preterm infants has become generally accepted since the work of Liggins and Howie. ${ }^{1}$ Nevertheless, there is disquieting experimental evidence of adverse effects on the growth of newborn animals after intrauterine or neonatal exposure to corticosteroids. ${ }^{2-4}$ In particular Johnson and colleagues ${ }^{24}$ have demonstrated in rhesus monkeys that alterations in neonatal lung growth and mechanics may occur after only 3 days of antepartum betamethasone administration in a dose comparable with that used in human obstetric practice. The pulmonary effects appeared to be dose related. ${ }^{2}$ Ill effects have been reported for other animal species. ${ }^{3}$

This paper reports the results of lung function tests in a group of 15 infants of very low birthweight (VLBW; less than $1500 \mathrm{~g}$ ), 7 of whom had been exposed to perinatal corticosteroids. We sought evidence for any alteration in lung growth or mechanics during the first year of life that could have been associated with corticosteroid therapy.

\section{Patients}

During a prospective longitudinal study of the pulmonary sequelae of VLBW infants, we identified 15 infants who had little or no neonatal lung disease. Five had transient tachypnoea, ${ }^{5}$ requiring a brief period of added oxygen therapy. Two were mechanically ventilated by endotracheal tube for 15 and 24 hours, during transport and during and after operation for small-bowel resection, respectively.

The mothers of 7 of the infants had been given intramuscular dexamethasone (mean dose $21.1 \mathrm{mg}$ ) during the 4 days before delivery, the first dose having been given a mean of 37 hours before delivery. One of the mothers had received only $4 \mathrm{mg}$, whereas the other $6 \mathrm{had}$ all received at least $12 \mathrm{mg}$ dexamethasone. None of the other 8 infants had been exposed to corticosteroids. The mean birthweight and gestational age ${ }^{6}$ were significantly greater in the control group, which contained a high proportion of growthretarded infants (Table 1).

The infants were studied, as far as possible, at 6monthly intervals for up to 12 months. The older infants were sedated (trichloryl $100 \mathrm{mg} / \mathrm{kg}$ ) for whole-body plethysmography. Parental consent was obtained for the measurements, which were approved by the Research Ethics Committee.

\section{Methods}

In order to measure lung mechanics, the infant was placed in the right lateral position inside the plethysmograph. Once the infant was sleeping quietly, an oesophageal balloon catheter was inserted

Table 1 Perinatal data (mean values $\pm S E$ )

\begin{tabular}{lll}
\hline & $\begin{array}{l}\text { Control } \\
\text { group } \\
(n=8)\end{array}$ & $\begin{array}{l}\text { Dexamethasone } \\
\text { treated } \\
(n=7)\end{array}$ \\
\hline Birthweight (g) & $1326(52)^{* *}$ & $1124(82)$ \\
Gestational age (weeks) & $32 \cdot 9(0 \cdot 6)^{* * * *}$ & $30 \cdot 1(0 \cdot 6)$ \\
Male: female & $4: 4$ & $3: 4$ \\
Inborn: outborn & $6: 2$ & $5: 2$ \\
Light for gestational age $\dagger$ & 7 & 3 \\
Membranes ruptured $>24$ hours & 1 & 2 \\
Transient tachypnoea (see text) & 1 & 4 \\
Mechanical ventilation & 1 & 1 \\
\hline
\end{tabular}

** $P<0.01,{ }^{* * *} P<0.001$, SE standard error.

†Less than 10th centile weight-for-age. 1415 
orally into the stomach. Watching the oscilloscopic display of oesophageal pressure, the catheter was withdrawn slowly until the pressure signal became inverted, indicating that the balloon was then in the oesophagus. The rebreathing apparatus with its built-in pneumotachograph ${ }^{7}$ was then carefully manipulated into place, and the face mask sealed around the mouth and nose with Silicone putty, taking care to avoid pressure on the nose and to ensure a tight fit. The oesophageal balloon was then inflated bringing it into its working range. ${ }^{8}$ Pulmonary conductance $(\mathrm{Gp})$ and dynamic compliance (Cdyn) were calculated from at least 10 breaths of reasonable regularity.$^{9-11}$

Thoracic gas volume (TGV) and airways conductance (GAw) were measured by an adaptation of a plethysmographic technique ${ }^{12}$ in which the infant rebreathed heated humidified gas at BTPS, using a rebreathing apparatus containing occluding valves. ${ }^{7}$ The characteristics of the pressure transducers (Valedyne MP45-1 for oesophageal pressure, box pressure, and flow; SE Labs 1150 for mask pressure) and the amplifier/ultraviolet chart recorder (Emma, SE Labs) had previously been shown to be satisfactory for measurements at a basic respiratory frequency of up to $2 \mathrm{~Hz}^{8}$ The flow signal was electronically integrated to give tidal volume. TGV was calculated from at least 3 separate occlusions. Calculation of airways resistance RAW was based on changes in gas flow and alveolar (box) pressure between points of mid-iso-lung volume.

\section{Results}

Altogether 34 sets of observations were made during the study on the 15 patients, representing between 1 and 4 sets of measurements for each patient. RAw and Cdyn measurements were less complete than TGV recordings for technical reasons.
Table 2 Lung mechanics (mean values $\pm S E$ )

\begin{tabular}{lll}
\hline & $\begin{array}{l}\text { Control } \\
\text { group }\end{array}$ & $\begin{array}{l}\text { Dexamethasone } \\
\text { group }\end{array}$ \\
\hline $\begin{array}{c}\text { Specific airways conductance } \\
\text { (per } \mathrm{CmH}_{2} \mathrm{O} \text { per second)* }\end{array}$ & $\begin{array}{l}2 \cdot 2( \pm 0 \cdot 37) \times 10^{-4} \\
\text { n } 14\end{array}$ & n 18 \\
$\begin{array}{l}\text { Specific dynamic compliance } \\
\left.\text { (per } \mathrm{cmH}_{2} \mathrm{O}\right) \dagger\end{array}$ & $\begin{array}{l}6 \cdot 7( \pm 0 \cdot 31) \times 10^{-4} \\
\mathrm{n} 10\end{array}$ & \multicolumn{1}{c}{ n 7} \\
\hline
\end{tabular}

$\mathrm{n}=$ number of observations of each parameter.

*Gaw/TGV, † Cdyn/TGV.

The relationship between lung volume (TGV) and body weight was so close for the two groups that the regression lines could not be separately depicted (Figure). The values of lung volume were identical with those obtained in a control group of infants of $>1500 \mathrm{~g}$ birthweight studied in this laboratory $($ TGV $(\mathrm{ml})=14.5 \times$ body weight $(\mathrm{kg})+41.9)$. Growth-retarded infants had the same relationship between TGV and body weight as did the appropriately grown infants. There was no significant difference between the two groups for either dynamic compliance or airways conductance, normalised for lung volume (Table 2).

\section{Discussion}

The VLBW infants in this study had been born at a time when antenatal corticosteroids were not always considered in the management of preterm labour or delivery and when minor medical contraindications to corticosteroid administration (for example mild hypertension, rupture of membranes) were generally observed. This allowed us to find a control group of untreated infants, broadly similar in clinical state to those exposed to antenatal dexamethasone. The mothers of the treated group received between 4 and $48 \mathrm{mg}$ dexamethasone during the 6-96 hours before delivery, the mean amount being close to a generally accepted dose. ${ }^{1}$ All the infants were free of significant

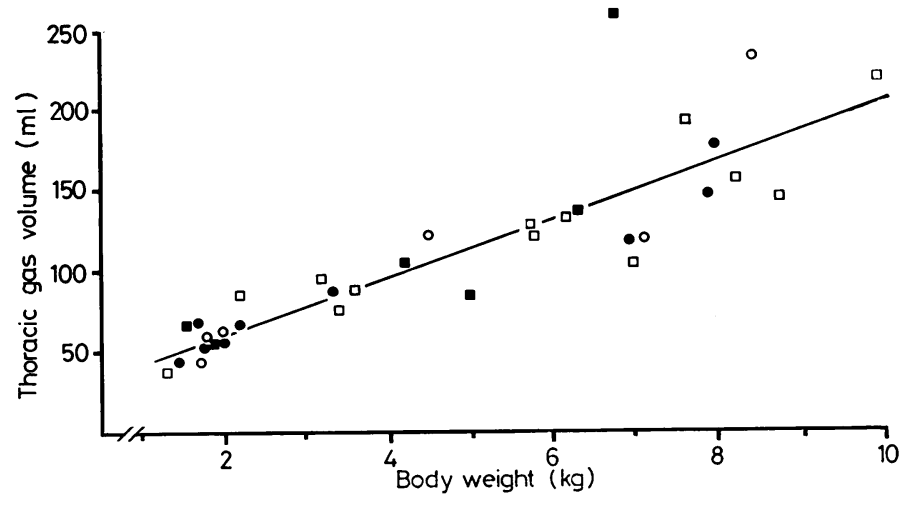

Figure Relationship between thoracic gas volume and body weight for control infants (circles) and dexamethasone-treated infants (squares); light for dates infants are shown by closed symbols. The calculated regression line for all the data points is shown. 
neonatal lung disease. Other VLBW infants, some exposed antenatally to dexamethasone and who developed neonatal respiratory disease, were of course admitted to our neonatal unit during the same period. They were not included in this study, since it would have been impossible to distinguish possible effects of dexamethasone from the effects of neonatal respiratory disease and its treatment.

No differences in TGV or lung mechanics were detected during the first year of life, between the control and dexamethasone-treated patients. Nor were any dose-related effects discernible when the results for high and low dose dexamethasone-treated infants were compared. The values of lung mechanics were in accord with our own laboratory values for infants of over $1500 \mathrm{~g}$ birthweight.

These results in human infants appear to contrast with observations on the lungs of preterm rhesus monkeys exposed in utero to similar amounts of corticosteroids. ${ }^{2}{ }^{4}$ In preterm monkeys, betamethasone produced an increase in lung distensibility (compliance) associated with altered alveolar morphology. The functional alterations were detected in saline-filled lungs and were thus independent of surface effects (that is, the surfactant system). It was speculated that long-lasting changes in the mechanical properties of the lungs might have resulted, although long-term follow-up studies were not carried out.

Our earliest studies were made in infants of 3-4 weeks' postnatal age. Moreover, our patients obviously had 'mature' lungs, since none suffered from respiratory disease syndrome. However, had any of the long-lasting effects predicted by Beck et $a .^{2}$ developed in our subjects, the consequent alterations in lung mechanics should have been detected by our tests, although, ideally, static pressure-volume curves of the lungs should have been performed. These have not been technically feasible in living infants.

This study has shown that exposure to antenatal dexamethasone had no ill-effect on the lung volume and lung mechanics of VLBW infants during their first year of life. Any major alteration in the structure or growth of the lungs should have been detected by our methods. This evidence, together with the evidence of other studies, ${ }^{13}$ suggests that the long-term risks of antenatal corticosteroid exposure in such infants may be minimal and are outweighed by the benefits. ${ }^{1}$

We thank Action Research-The National Fund for Research into Crippling Diseases, the Sir William
Coxen Fund, and the Medical Research Council for financial support.

\section{References}

1 Liggins G C, Howie R N. A controlled trial of antepartum glucocorticoid. Treatment for prevention of the respiratory distress syndrome in premature infants. Pediatrics 1972; 50: 515-25.

2 Beck J C, Mitzner W, Johnson J W C, et al. Betamethasone and rhesus fetus: effect on lung morphometry and $\mathcal{Q}$ connective tissue. Pediatr Res $1981 ; 15$ : 235-40.

3 Frank L, Summerville J, Massaro D. The effect of prenatal $\vec{O}$ dexamethasone treatment on oxygen toxicity in the newborn rat. Pediatrics 1980 ; 65: 287-93.

4 Johnson J W C, Mitzner W, London W T, Palmer A E, Scott R. Betamethasone and the rhesus fetus: multi- 응 systemic effects. Am J Obstet Gynecol 1979; 133: 677-84.

5 Avery M E, Fletcher B D. The lung and its disorders in the or newborn infant, third edition. Major Problems in Clinical : V Pediatrics. Vol. 1. Philadelphia: Saunders, 1974: 199-208, 268-71.

6 Dubowitz L M S, Dubowitz V, Goldberg C. Clinical O assessment of gestational age in the newborn infant. $J$ Pediatr 1970; 77: 1-10.

7 Stocks J, Levy N M, Godfrey S. A new apparatus for the accurate measurement of airway resistance in infancy. $J \stackrel{一}{<}$ Appl Physiol 1977; 43: 155-9.

8 Beardsmore C S, Helms P, Stocks J, Hatch D J, Silverman $\overrightarrow{0}$ M. Improved esophageal balloon technique for use in $N$ infants. J Appl Physiol 1980; 49: 735-41.

- Cook C D, Sutherland J M, Segal S, et al. Studies of respiratory physiology in the newborn infant. III. Measurements of mechanics of respiration. $J$ Clin Invest 1957; 36: 440-8.

10 Karlberg P, Cherry R B, Escardo F, Koch G. Respiratory studies in newborn infants. I. Apparatus and methods for studies of pulmonary ventilation and the mechanics of breathing. Acta Paediatr Scand 1960; 49: 345-57.

11 Krieger I. Studies on mechanics of respiration in infancy. Am J Dis Child 1963; 105: 439-48.

12 Dubois A B, Botelho S Y, Bedell G N, Marshall R, Comroe $\mathrm{J}$ H, Jr. A rapid plethysmographic method for measuring thoracic gas volume: a comparison with a nitrogen washout method for measuring functional residual capacity in normal subjects. $J$ Clin Invest 1956 ; 35: 322-6.

13 Liggins G C. Prenatal glucocorticoid treatment: prevention of respiratory distress syndrome. In: Moore T D, ed. Lung maturation and the prevention of hyaline membrane disease. Report of the Seventieth Ross Conference on Pediatric Research, Puerto Rico, 1976. Columbus, Ohio: Ross Laboratories, 1976: 97-103.

14 Babson S G, Behrman R E, Lessel R. Fetal growth. Liveborn weights for gestational age of white middle class infants. Pediatrics $1970 ; 45: 937-44$.

15 Thomson A M, Billewicz W Z, Hytten F E. The assessment of fetal growth. J Obstet Gynaecol Br Commonw 1968 ; 75 : 903-16.

Correspondence to Dr M Silverman, Department of $\bullet$ Paediatrics and Neonatal Medicine, Hammersmith Hospital, Du Cane Road, London W12 OHS.

Received 26 February 1982 